\title{
The phytochemical and chemotaxonomic study of Salvia spp. growing in Ukraine
}

\author{
Oleh Koshovyi ${ }^{1}$, Ain Raal ${ }^{2, *}$, Alla Kovaleva ${ }^{1}$, Mykhailo Myha $^{1}$, Tetyana Ilina ${ }^{1}$, Natalia Borodina ${ }^{1}$, Andrey Komissarenko $^{1}$ \\ ${ }^{1}$ Pharmacognosy Department, The National University of Pharmacy, Pushkinska st 53, 61002 Kharkiv, Ukraine. \\ ${ }^{2}$ Institute of Pharmacy, Faculty of Pharmacy, University of Tartu, Nooruse 1, 50411 Tartu, Estonia.
}

\begin{tabular}{l}
\hline ARTICLE INFO \\
\hline Article history: \\
Received on: October 10, 2019 \\
Accepted on: February 25, 2020 \\
Available online: May 26, 2020 \\
\hline
\end{tabular}

Key words:

Sage, chemotaxonomy, terpenoids, polyphenols, gas chromatography, HPLC.

\begin{abstract}
Salvia officinalis is a well-studied and popular medicinal plant containing toxic thujones, rather limited phytochemical and pharmacological studies have been performed on other Salvia spp. The aim of the study was to perform phytochemical and chemotaxonomic studies of Salvia genus species $(n=16)$ from Ukraine to identify the most promising species for the pharmaceutical industry. The content of essential oils from the leaves of 16 Salvia spp. has been studied by gas chromatography/mass spectrometry (MS) and polyphenols by high performance liquid chromatography/MS, and a chemotaxonomic study has been performed by calculation of coefficients of occurrence, originality, and pair affinity. The Salvia spp. is characterized by the presence of monoterpenoids, hydroxycinnamic acids - derivatives of caffeic acid, and flavonoids - derivatives of luteolin and apigenin. The highest content of essential oil is observed in the leaves of S. officinalis, S. grandiflora, and S. scabiosifolia $(1.41 \%-1.85 \%)$. The highest amount of hydroxycinnamic acids is in the leaves of S. pratensis, S. illuminata, $S$. austriaca, and $S$. verticillata; the highest content of flavonoids and phenolic compounds is found in the leaves of S. grandiflora, S. pratensis, S. illuminata, S. nemorosa, S. pendula, S. sylvestris, $S$. nutans, $S$. verticillata, and $S$. cernua. The chemical profile of the genus has been determined; it is characterized by terpenoids such as $\alpha$ - and $\beta$-pinene, camphane derivatives (camphene, camphor, and borneol), $p$-cymene, 1,8-cineol, limonene, phenolic compounds (caffeic and rosmarinic acids), and flavonoids (cynaroside, cosmosiin, hispidulin, and cirsimaritin). A rather high concentration of toxic _- and _thujone is typical only in the essential oil of S. officinalis (33.6\% and $6.5 \%$, respectively). The most promising species for use in the pharmaceutical industry are S. grandiflora, S. cernua, S.pratensis, S. nemorosa, and S. verticillata.
\end{abstract}

\section{INTRODUCTION}

The genus Salvia is one of the largest genera from the Lamiaceae family which comprises 700 species and is widely distributed in various regions of the world [1]. Of 151 pharmacopoeial species of medicinal plants grown on the territory of Ukraine, sufficient reserves are available only for 47 wild species, 32 species are cultivated; as a whole, it is $52 \%$. There are 38 species $(25 \%)$ that are in insufficient quantities in Ukraine, and it leads to a shortage of the raw material and the need to import it; moreover, 34 species $(23 \%)$ should be imported for the needs of the Ukrainian pharmaceutical industry. Therefore, the relevance of the systematic scientific search for the medicinal plant raw material containing important

\footnotetext{
*Corresponding Author

Ain Raal, Institute of Pharmacy, Faculty of Pharmacy, University of Tartu, Nooruse 1,50411 Tartu, Estonia.E-mail: ain.raal@ut.ee
}

biologically active substances among plants of the Ukrainian flora and its introduction into the register of officinal medicinal plants is undeniable [2-5].

Over the past 10 years, a substantial literature dataset regarding the pharmacological properties of biologically active compounds contained in the representatives of the Salvia spp. that are presented, in particular, in the flora of Ukraine has been accumulated. For example, in recent works, it is shown that extracts of some representatives of the Salvia genus can inhibit hyperglycemia and lipid peroxidation, increase the activity of antioxidant enzymes, as well as reduce the frequency of hot flushes during menopause up to $100 \%$ [6,7]. Biologically active substances of Salvia improve memorization processes, and exhibit anxiolytic effect and a high level of cholinesterase inhibition [8-11]. It may have significant therapeutic potential in the treatment of central nervous system diseases, in particular, Alzheimer's disease [12,13]. 
Previously, the content of amino acids and monosaccharides has been studied in Salvia spp. growing in Ukraine [14]. Also, terpenoids and phenolic compounds have been analyzed in Salvia officinalis and some other species $[5,15,16]$. The chemical composition of other species of Salvia growing in Ukraine and their use in pharmaceutical and medical practice have not been practically studied. Very limited mechanistic studies and very little in vitro tests have been performed on the biologically active substances in Salvia spp. [17].

Chemosystematic studies clarify the position of the species object in the genus system and are carried out with the aim of clarifying the systematics of individual species; search for promising species for using in medicine; and to identify correlative relationships between the morphological structure, environmental conditions of existence, and the chemical composition of plants [18-20]. The modern classification of plants is based on their botanical structure, primarily the signs of their generative organs, it is based on a subjective approach to the description of plants and does not always correspond to the true state of things. Chemosystematics is one of the sources of information for synthetic integral systematics, which is more likely to recreate the true picture of the evolutionary development of taxa (species) of plants than any other extraneous approach to solving this problem $[21,22]$.

Some species of Salvia genus were studied by chemosystematics in different countries, and using secondary metabolism substances as chemo attributes: terpenoids [23-25], as well as substances primary metabolism: fatty oils [26], although the latter is doubtful because of chemotaxonomic originality deprivation.

The aim of our work was to search for sources of biologically active substances among species of the genus Salvia, growing in Ukraine, using phytochemical and chemotaxonomic research methods. This helps to indicate the prospects of the in-depth study of these species for the needs of the pharmaceutical industry and to show the expediency of further research to create new drugs. According to the authors' hypothesis, not only S. officinalis, but also other Salvia spp. have promising pharmaceutical value.

\section{MATERIALS AND METHODS}

\subsection{Plant Material}

Of 21 species of the Salvia spp. presented in the flora of Ukraine, 16 species ( $S$. officinalis, $S$. sclarea, S. grandiflora, S. scabiosifolia, S. glutinosa, S. aethiopis, S. pratensis, S. stepposa, S. Sibthorpii, S. illuminata, S. nemorosa, S. pendula, S. sylvestris, S. nutans, S. austriaca, $S$. verticillata, and $S$. cernua) were studied. Data of Salvia sclarea for the chemotaxonomic study were taken from scientific literature $[5,15,27,28]$. The leaves of different Salvia spp. were harvested at the beginning of flowering in the Botanical Garden of V. N. Karazin Kharkiv National University (5001'33.7'N 36 13 '46.3'E). All collected plants were already planted as samples of different Salvia spp. in the botanical garden; they were not planted by the authors of the paper. The leaves have been collected from one plant of each studied species and were dried at room temperature in a well-ventilated area for ten days. The species Salvia genus studied were identified by prof. Yu. H. Hamulia from the V. N. Karazin Kharkiv National University using a special botanical catalog [29]. The voucher specimens are stored at the Department of Pharmacognosy, The National University of Pharmacy, Kharkiv, Ukraine (No. 172-188).

\subsection{Isolation of Essential Oils}

Essential oil was isolated from the dried leaves of the Salvia spp. $(10 \mathrm{~g})$ by simultaneous distillation and extraction (SDE) with n-hexane (Fluka $>99 \%$ ) as a solvent $(0.5 \mathrm{ml})$ via a Marcusson type micro-apparatus [30]. The SDE process was carried out for 2 hours. The oil amount (\%) was determined using n-tetradecane (Reaching $>99 \%)$ as an internal standard $(2 \mu \mathrm{l})$ [31]. The reproducibility of three parallel SDE procedures with a single sample showed the variation coefficient to be below $20 \%$.

\subsection{Analysis of the Essential Oils}

The qualitative composition and the quantitative content of terpenoids have been determined by gas chromatography using an Agilent Technology 6,890 chromatograph with a mass spectrometric detector 5,973 under standard conditions: HP-5 on fused silica capillary columns with bonded stationary phases SPB-5 $(30 \mathrm{~m}$ $\times 0.25 \mathrm{~mm}$, Supelco), film thickness of stationary phases was $0.25 \mu \mathrm{m}$. The temperature program was from $50^{\circ} \mathrm{C}$ to $250^{\circ} \mathrm{C}$ at $4{ }^{\circ} \mathrm{C} /$ $\mathrm{min}$, and the injector temperature was $250^{\circ} \mathrm{C}$. Injection volume: 2.0 $\mu \mathrm{l}$, two injections were carried out. Carrier gas He with split ratio $150: 1$, and the flow rate of $1 \mathrm{ml} / \mathrm{min}$ was applied. The temperature of the interface: $250^{\circ} \mathrm{C}$; ion source temperature: $230^{\circ} \mathrm{C}$. The mass spectrometry (MS) detector was operated in the electron ionization mode $70 \mathrm{eV}$ at a scan rate of $2 \mathrm{scans} / \mathrm{sec}$ with an acquisition mass range of 29-450 a.m.u.

The identification of compounds was performed based on the comparison of the mass spectra obtained with the data from the NIST05-WILEY library (approximately 500,000 mass spectra) [30]. The retention indices of the components were calculated based on the results of control analyses of compounds when adding a mixture of normal alkanes $\left(\mathrm{C}_{10}-\mathrm{C}_{18}\right)$. The yield of the essential oil was calculated by the sum of all peak areas on the chromatograms.

\subsection{Sample Preparation, high performance liquid chromatography (HPLC)-diode array detector-MS/MS Analysis, and Quantification}

About $500.0 \mathrm{mg}$ (exact weavage) of Salvia spp. leaves were weighed in a $5.0 \mathrm{ml}$ measuring tube and brought to the mark with $90 \%$ aqueous methanol. After 30 minutes in an ultrasonic bath, the sample was insisted at room temperature for 3-4 hours. The test tube was again placed on an ultrasound bath for 15 minutes, and then the solution was filtered through a Teflon filter with a pore size of $0.45 \mu \mathrm{m}$ in a vial for analysis.

Separation, identification, and quantification of phenolic compounds were determined by HPLC using an Agilent Technologies chromatograph (model 1100) equipped with a vacuum degasser G1379A, four-channel low-pressure gradient pump G13111A, automatic injector G1313A, G13116A column thermostat, and G1316A diode-matrix detector. Columns, $2.1 \mathrm{~mm}$ $\times 150 \mathrm{~mm}$, were filled with octadecylsilyl sorbent grains of $3.5 \mu \mathrm{m}$ "ZORBAX-SB C-18." The analysis of methanol extracts from Salia spp. leaves was carried out under the following conditions: thermostat temperature: $35^{\circ} \mathrm{C}$; flow rate of the mobile phase: 
$0.25 \mathrm{ml} / \mathrm{min}$; as a mobile phase: solution A $(0.1 \% \mathrm{H} 3 \mathrm{PO} 4,180$ $\mu \mathrm{l} / \mathrm{l}$ triethylamine, $3 \mathrm{ml} / 1$ tetrahydrofuran in water) and solution $\mathrm{B}$ $(\mathrm{MeOH})$ in the ratio of 90:10 (first 8 minutes), 70:30 (from 8 for 24 minutes), and from 24 minutes only solution B was used; and working pressure of the eluent: $240-300 \mathrm{kPa}$. In the analysis, the following detection parameters were set: scale of measurement: 1,0; scan time: 0.5 second; the parameters for removing the spectrum: each peak is $190-600 \mathrm{~nm}$. The identification of phenolic compounds was performed by the retention time of standards and ultraviolet spectral characteristics.

\subsection{Chemotaxonomic Study}

For the chemotaxonomic study, the data from the scientific literature of $S$. sclarea and other species were used [5,15,27,28]; 5719 states of signs being characteristic of terpenoids and phenolic compounds were analyzed. The coefficients of originality, the informational content of the sign, the sums of positive normal and qualified states of signs used for further calculations in taxonomy, as well as the coefficients of pair and group affinity were calculated [32-34].

The coefficient of occurrence (Coc) traits was calculated by the formula:

$$
\operatorname{Coc}=\frac{\mathrm{M}}{\mathrm{N}} \times 100
$$

where $\mathrm{M}$ - the total number of occurrence of this trait;

$\mathrm{N}=\mathrm{S}$ is the sum of the positive and negative states of the feature, which is equal to the S-population of the object being studied or the number of species (taxons).

The coefficient of originality (Cor) traits was calculated by the formula:

$$
\operatorname{Cor}=\left(1-\frac{M}{N}\right) \times 100=100-\operatorname{Coc}
$$

Informative character (sign weight) was calculated by the formula:

$$
\mathrm{JPi}=\frac{\mathrm{N}}{2}-\mathrm{n}
$$

where $\mathrm{n}$ is the sum of positive states of signs.

The peculiarity (A), or informational, of taxons were determined only for positive values of JPi:

$$
\mathrm{A}=\Sigma \mathrm{JPi}
$$

The calculation of coefficients of pair affinity (CPA) was carried out according to the formula: coefficient of pair affinity

$$
\mathrm{CPA}=\left(\frac{\mathrm{P}}{\mathrm{P}}+\mathrm{d}\right) \times 100
$$

where $P$ is the number of positive signs and $d$ is the sum of states of attributes that are different.

In turn

$$
\mathrm{P}=\mathrm{P} 1+\mathrm{P} 2
$$

where $\mathrm{P} 1$ is the sum of the positive normal states of signs and P2 is the sum of positive qualifying states of attributes.

The value of the coefficients of the pair affinity characterizes the interspecific relationship or the taxonomic distance between the species. The calculations were carried out using the program Microsoft Excel 2010.

The signs and taxons were given numbering accordingly to it they were placed in the matrix table. The presence of signs was marked with the number " 1 ", while in the absence of a sign the cell was left empty, i.e., the continuum of the values was in the range from 0 to 1 . The table served as the basis for the numerical quantitative taxonomic analysis: calculations of the information weight of the signs, frequency indices, originality of signs, and distinctness of taxons $[33,34]$. Using the signs of the morphological structure and the chemical composition, the coefficients of pair and group affinity of the species of the Salvia genus were calculated. The values of the CPA characterize the interspecific relationship or the taxonomic distance between the species. Taking into account the CPA and the coefficients of group affinity, the dendrograms characterizing the taxonomic distances between species of the genus by chemical signs were constructed.

\subsection{Statistics}

The leaves have been collected from one plant of each studied species of Salvia spp., therefore no statistics were performed. The standard deviation of used methods does not exceed $5 \%$.

\section{RESULTS AND DISCUSSION}

\subsection{Composition of Essential Oils}

The content of the main components of the essential oils in the leaves of Salvia spp. is shown in Table 1. In general, 185 substances were found in the objects studied; among them, 114 substances were identified. The highest content of essential oil $(0.32 \%-1.85 \%)$ was observed in the leaves of $S$. officinalis, S. grandiflora, and S. scabiosifolia. It indicates the expediency of further study of these species in order to create new drugs.

In the leaves of $S$. officinalis 28 compounds were found; among them, 1,8-cineol, $\alpha$-pinene, $\alpha$ - and $\beta$-thujone, camphene, camphor, borneol, bornylacetate, caryophyllene, caryophyllene oxide, viridiflorol, humulene, humulene oxide, and manool dominated. Similar results have been shown in the study of essential oils of S. officinalis from different countries [35] where the level of toxic _- and _thujone was 3.0\%-26.6\% and $1.5 \%-12.9 \%$, respectively. Other Salvia spp. studied by us do not contain thujones or their concentration was very low $(0.05 \%-0.2 \%)$, and they are safe. Thujone as a modulator of $\mathrm{GABA}_{\mathrm{A}}$ receptor can act as a convulsant, it may have benefits within the safety limit, such as anxiolytic and antipsychotic actions, also in suppressing dementia symptoms [36].

The leaves of $S$. grandiflora and $S$. scabiosifolia contain 1,8-cineol, $\alpha$ - and $\beta$-pinene which have antibacterial activities. The antibacterial activity has been shown for extracts of many different Salvia spp. [17,37-39]. The leaves of essential oils from other Salvia spp. typically contain heptacosane, nonacosane, hentriacontane, and tritriacontane as principal compounds. 
Table 1: Composition (\%) of essential oils of Salvia spp. leaves from Ukraine.

\begin{tabular}{|c|c|c|c|c|c|c|c|c|c|c|c|c|c|c|c|c|}
\hline Compounds & 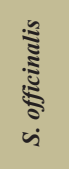 & 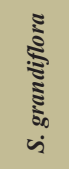 & 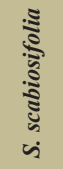 & 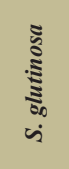 & 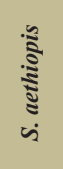 & 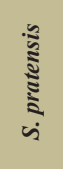 & 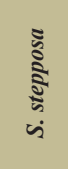 & 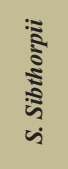 & 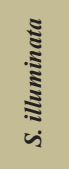 & 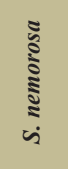 & 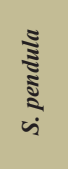 & 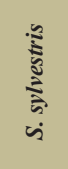 & 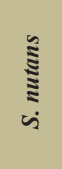 & 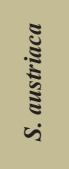 & 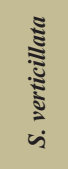 & 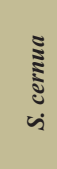 \\
\hline$\alpha$-Pinene & 1.5 & 22.5 & 1.1 & 0 & 0 & 0.10 & $<0.1$ & 0.1 & 0 & 2.8 & 0 & 0.1 & 0 & 0.6 & 0 & 0 \\
\hline Camphene & 2.6 & 5.1 & 3.9 & 0 & 0 & 0 & 0 & 0.2 & 0 & 0.4 & 0 & $<0.1$ & 0 & 0.2 & 0 & 0 \\
\hline Sabinene & 0 & 0 & 2.7 & 0 & 0 & 0 & 0 & 0 & 0 & 0 & 0 & 0 & 0 & 0 & 0 & 0 \\
\hline$\beta$-Pinene & 0 & 12.3 & 2.7 & 0 & 0 & 0 & 0 & $<0.1$ & 0 & 1.2 & 0 & 0 & 0 & $<0.1$ & 0 & 0 \\
\hline$p$-Cymene & 0.2 & 3.6 & 2.3 & 1.1 & 0 & 0 & 0 & 2.2 & 0 & 42.1 & 0 & 0 & 0 & 0 & 0.1 & 0 \\
\hline 1,8-Cineol & 8.5 & 3.5 & 4.0 & 0 & 0 & 0.3 & $<0.1$ & $<0.1$ & 0 & 0.4 & 0 & $<0.1$ & 0 & $<0.1$ & $<0.1$ & 0.2 \\
\hline Limonene & 0 & 2.1 & 0.7 & 0.1 & 0 & 0 & 0.1 & $<0.1$ & 0 & 0.1 & 0 & $<0.1$ & 0 & $<0.1$ & $<0.1$ & $<0.1$ \\
\hline cis-Sabinene hydrate & 0 & 0 & 2.3 & 0 & 0 & 0 & 0 & 0 & 0 & 0 & 0 & 0 & 0 & 0 & 0 & 0 \\
\hline Dehydro-p-cymene & 0 & 0 & 0 & 0 & 0 & 0 & 0 & 0.1 & 0 & 4.1 & 0 & 0 & 0 & 0 & 0 & 0 \\
\hline$\beta$-Thujone & 6.5 & 0 & 0 & 0 & 0 & 0 & 0 & $<0.1$ & 0 & 1.1 & 0 & 0 & 0 & 0 & 0 & 0 \\
\hline$\alpha$-Thujone & 33.6 & 0 & 0.2 & 0 & 0 & 0 & 0 & 0 & 0 & 0 & 0 & 0 & 0 & 0 & 0 & 0 \\
\hline Camphor & 19.8 & 10.1 & 22.2 & 0 & 0 & 0 & 0 & 0 & 0 & 1.2 & 0 & 0 & 0 & $<0.1$ & 0 & 0 \\
\hline Pinocarvone & 0 & 2.9 & 0 & 0 & 0 & 0 & 0 & 0 & 0 & 0.8 & 0 & 0 & 0 & 0 & 0 & 0 \\
\hline Borneol & 4.4 & 5.6 & 0 & 0 & 0 & 0 & 0 & 0 & 0 & 0 & 0 & 0 & 0 & 0 & 0 & 0 \\
\hline Menthol & 0 & 0 & 0 & 0 & 0 & 0 & 0 & 0 & 0 & 0 & 0.1 & 0 & 0 & 0 & 0 & 0 \\
\hline trans-2-Decenal & 0 & 0 & 0 & 0 & 0.6 & 0.3 & 1.2 & 0.7 & 0 & 2.2 & 0 & 0 & 0 & 0 & 0 & 0 \\
\hline Bornylacetate & 2.4 & 0 & 0 & 0 & 0 & 0 & 0 & 0 & 0 & 0 & 0 & 0 & 0 & 0 & 0 & 0 \\
\hline$\alpha$-Copaene & 0 & 4.1 & 0 & 0 & 0 & 0 & 0 & 0 & 0 & 0 & 0 & 0 & 0 & 0 & 0 & 0 \\
\hline$\beta$-Burbonene & 0 & 0.5 & 6.9 & 0 & 0 & 0 & 0 & 0 & 0 & 0 & 0 & 0 & 0 & 0 & 0 & 0 \\
\hline Caryophyllene & 1.2 & 0.5 & 0 & 0 & 0 & 0 & 0 & 0 & 0 & 0 & 0 & 0 & 0 & 0 & 0 & 0 \\
\hline Tetradecane & 0 & 0 & 0 & 2.8 & 1.4 & 1.5 & 3.0 & 0.9 & 1.7 & 7.1 & 0.5 & 0 & 0.6 & 2.1 & 1.4 & 2.4 \\
\hline$\alpha$-Amorfen & 0 & 6.4 & 0 & 0 & 0 & 0 & 0 & 0 & 0 & 0 & 0 & 0 & 0 & 0 & 0 & 0 \\
\hline Dihydroactinidiolide & 0 & 0 & 0 & 0 & 0 & 0 & 0 & 0 & 0 & 0 & 0.6 & 0 & 0 & 0 & 0.6 & 0 \\
\hline 1,5-Epoxysalvial-4(14)-ene & 0 & 0 & 0 & 0 & 0 & 0 & 0 & 0 & 0 & 0 & 0 & 0 & 1.0 & 0 & 0 & 0 \\
\hline Caryophyllene oxide & 1.4 & 0.8 & 0 & 0 & 0 & 0 & 0 & 0 & 0 & 0 & 0 & 0 & 0 & 0 & 1.6 & 0 \\
\hline Spathulenol & 0 & 0 & 3.9 & 0 & 0.3 & 0 & 0 & 0 & 0 & 0 & 0 & 0 & 0 & 0 & 0 & 0 \\
\hline Viridiflorol & 7.7 & 0.8 & 0 & 0 & 0 & 0 & 0 & 0 & 0 & 0 & 0 & 0 & 0 & 0 & 0 & 0 \\
\hline Humulene & 2.1 & 0 & 0 & 0 & 0 & 0 & 0 & 0 & 0 & 0 & 0 & 0 & 0 & 0 & 0 & 0 \\
\hline Hexahydrofarnesyl acetone & 0 & 0 & 0 & 0 & 0.4 & 2.3 & 2.2 & 1.6 & 2.1 & 6.3 & 1.0 & 0 & 1.8 & 0 & 2.1 & 0.8 \\
\hline cis-Neofitadiene & 0 & 0 & 0 & 0 & 0 & 0.6 & 1.0 & 2.0 & 0.6 & 16.9 & 1.1 & 1.1 & 1.0 & 0 & 0.9 & 1.3 \\
\hline Humulene oxide & 1.6 & 0 & 0 & 0 & 0 & 0 & 0 & 0 & 0 & 0 & 0 & 0 & 0 & 0 & 0 & 0 \\
\hline cis- and trans-Neofitadiene & 0 & 0 & 0 & 0 & 0 & 0 & 0 & 0 & 0 & 3.6 & 0.2 & 0 & 0 & 0 & 0 & 0.2 \\
\hline Manool & 3.0 & 0.9 & 0 & 0 & 0 & 0 & 0 & 0 & 0 & 0 & 0 & 0 & 0 & 0 & 0 & 0 \\
\hline Heneicosane & 0 & 0 & 0.6 & 0 & 1.4 & 1.2 & 1.4 & 0 & 0 & 6.5 & 0.7 & 1.3 & 1.2 & 1.2 & 1.9 & 1.2 \\
\hline Docosane & 0 & 0 & 0.9 & 0 & 1.1 & 1.4 & 0.9 & 0.5 & 0.5 & 6.6 & 1.9 & 0.8 & 1.1 & 1.3 & 2.4 & 1.4 \\
\hline Pentacosane & 0 & 0 & 1.4 & 0.7 & 1.7 & 1.3 & 1.0 & 0.6 & 0.5 & 7.7 & 0.6 & 0.5 & 0.7 & 3.6 & 2.0 & 0.7 \\
\hline Heptacosane & 0 & 0 & 0.6 & 4.1 & 2.4 & 3.5 & 2.4 & 1.3 & 1.2 & 11.4 & 1.4 & 1 & 2.5 & 9.2 & 2.3 & 1.2 \\
\hline Nonacosane & 0 & 0 & 2.0 & 13.0 & 3.7 & 8.7 & 5.3 & 4.5 & 5.3 & 42.4 & 7.0 & 4.4 & 5.4 & 16.4 & 11.5 & 4.8 \\
\hline Hentriacontane & 0 & 0 & 5.3 & 24.0 & 11.9 & 10.4 & 15.3 & 10.5 & 18.6 & 63.2 & 20.8 & 14.2 & 19.0 & 11.1 & 0 & 3.0 \\
\hline Dotriacontane & 0 & 0 & 0.9 & 2.6 & 4.5 & 4.4 & 3.6 & 2.9 & 5.0 & 35.6 & 4.1 & 4.8 & 2.7 & 1.9 & 1.1 & 1.6 \\
\hline$\gamma$-Sitosterol & 0 & 0 & 0 & 0 & 0 & 3.1 & 4.0 & 0 & 3.1 & 11.7 & 0 & 5.3 & 0 & 5.3 & 2.9 & 2.5 \\
\hline Tritriacontane & 0 & 0 & 8.7 & 16.3 & 28.8 & 16.9 & 12.9 & 11.7 & 23.0 & 11.6 & 25 & 33.4 & 12.3 & 7.6 & 15.6 & 10.9 \\
\hline Tetratriacontane & 0 & 0 & 0 & 0 & 7.4 & 0 & 0 & 0 & 0 & 0 & 0 & 3.1 & 0 & 0 & 0 & 0 \\
\hline Content of essential oil (\%) & 1.85 & 1.45 & 1.41 & 0.43 & 1.35 & 0.44 & 0.32 & 0.38 & 0.58 & 0.62 & 0.92 & 0.28 & 0.61 & 0.69 & 0.43 & 0.47 \\
\hline $\begin{array}{l}\text { Number of compounds } \\
\text { in essential oils }\end{array}$ & 28 & 34 & 35 & 29 & 47 & 47 & 47 & 57 & 31 & 57 & 37 & 33 & 32 & 30 & 35 & 37 \\
\hline
\end{tabular}




\subsection{Polyphenols}

$\mathrm{Wu}$ et al. [38] classified the polyphenols in Salvia spp. into two subgroups: phenolic acids and flavonoids, which play an important role in the prevention of human diseases. In the leaves of S. officinalis, 13 substances of phenolic nature were found; among them, caffeic, 3,4-dicaffeoylquinic and rosmarinic acids, apigenin, luteolin, 3-methoxyluteolin, and cosmosiin were identified (Table 2). For the first time in 16 species of Salvia in the flora of Ukraine, 60 substances of phenolic nature were found; among them, 14 substances were identified. In the leaves of the species studied, there are mainly derivatives of flavones: luteolin and apigenin. In addition, the leaves of S. stepposa, S. Sibthorpii, and S. cernua also contain derivatives of kaempferol and quercetin. The highest content of hydroxycinnamic acids is observed in the leaves of S. pratensis, S. illuminata, S. austriaca, and S. verticillata. The highest content of flavonoids and phenolic compounds is in the leaves of $S$. grandiflora, $S$. pratensis, $S$. illuminata, $S$. nemorosa, $S$. pendula, $S$. sylvestris, $S$. nutans, $S$. verticillata, and $S$. cernua; it indicates the prospects of the in-depth study of these species for the needs of the pharmaceutical industry.

Thus, the highest quantitative content of phenolic compounds is typical for the leaves of $S$. grandiflora, S. pratensis, S. illuminata, S. nemorosa, S. pendula, S. sylvestris, S. nutans, S. verticillata, and $S$. cernua; it indicates the prospects of using these species as sources of phenolic biologically active substances.

In the study [6], a close correlation was shown between the total phenol contents and the antioxidant activities of the Salvia extracts. The plants of the genus Salvia are typically rich in antioxidant polyphenols and abietane diterpenoids such as rosmarinic acid, which showed considerable anticancer and antimicrobial activity
[7]. S. officinalis contains less rosmarinic acid $(596 \mathrm{mg} / \mathrm{kg})$ than ten other Salvia spp. studied (1,123-12,310 mg/kg), the difference between minimum and maximum content is more than 20 times. Rosmarinic acid and carnosol were the main compounds in all the antioxidant phenolic extracts isolated from S. officinalis [38]. It also has antihepatitis, inhibition of HIV-1, and hepatoprotection effects [40]. Salvia spp. and their individual active constituents may also impact on neurological and cognitive function [41]. Especially, caffeic acid derivatives play an important role as potent antiviral agents in Salvia spp. [17].

In addition to terpenoids in essential oils and polyphenols, diterpenes and triterpenoids are important constituents in Salvia spp., more than 200 triterpenoids of different classes were isolated from 113 species of the genus [1]. Salvia spp. have been reported as showing antioxidant, antimicrobial, antiinflammatory, antidiabetic, anti-HIV, anti-Alzheimer's disease, antileishmanial, antimalarial, antiprotozoal, and cytotoxicity activities [17,42], which may be also characteristic to the Salvia spp. studied by us in addition to $S$. officinalis. From these objects, only some species passed the studies of their activities, for example, the methanol extract of $S$. aethiopsis has been shown antioxidant activity [38].

\subsection{Determination of Promising Species of the Salvia Genus as Sources of Biologically Active Substances}

As a result of the study of the chemical composition of Salvia in the flora of Ukraine, it has been found that the genus is characterized by the presence of monoterpenoids, hydroxycinnamic acids - derivatives of caffeic acid and flavonoids - derivatives of luteolin and apigenin.

For the chemotaxonomic study (Figs. 1-2) of the Salvia genus, 5,719 states of 301 chemo signs being characteristic of terpenoids

Table 2: Content of individual phenolic compounds $(\mathrm{mg} / \mathrm{kg})$ and their groups $(\%)$ in Salvia spp. leaves from Ukraine.

\begin{tabular}{|c|c|c|c|c|c|c|c|c|c|c|c|c|c|c|c|c|}
\hline Compounds & 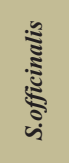 & 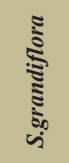 & 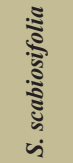 & 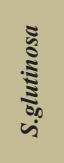 & 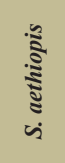 & 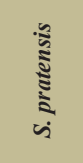 & 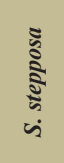 & 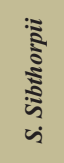 & 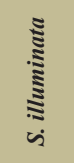 & 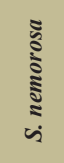 & 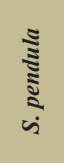 & 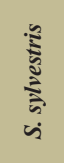 & 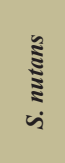 & 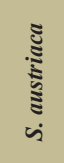 & 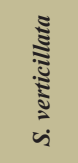 & $\begin{array}{c}\mathbb{\Xi} \\
\stackrel{\Xi}{\Xi} \\
\dot{\Xi}\end{array}$ \\
\hline Caffeic acid & 129 & 188 & 108 & 44 & 39 & 118 & 26 & 87 & 258 & 138 & 37 & 191 & 89 & 245 & 294 & 30 \\
\hline Vicenin-2 & 0 & 964 & 0 & 0 & 0 & 0 & 0 & 0 & 0 & 0 & 0 & 0 & 1428 & 0 & 0 & 375 \\
\hline 3,4-Dicoffeilquinic acid & 86 & 0 & 0 & 0 & 0 & 0 & 0 & 0 & 0 & 0 & 0 & 0 & 0 & 0 & 0 & 0 \\
\hline Cynaroside & 1955 & 6209 & 1255 & 203 & 198 & 11493 & 245 & 673 & 1931 & 5494 & 224 & 1395 & 2349 & 435 & 6886 & 3992 \\
\hline Rutin & 0 & 0 & 0 & 0 & 0 & 0 & 358 & 409 & 0 & 0 & 0 & 0 & 0 & 0 & 0 & 614 \\
\hline Rosmarinic acids & 596 & 4601 & 4625 & 53 & 552 & 6899 & 1223 & 1123 & 6811 & 3100 & 92 & 3489 & 112 & 4147 & 12310 & 521 \\
\hline Cosmosiin & 0 & 1651 & 1107 & 0 & 218 & 0 & 0 & 209 & 0 & 0 & 0 & 1015 & 512 & 0 & 4070 & 1887 \\
\hline Kaempferol-3-O-glucoside & 0 & 0 & 0 & 0 & 0 & 0 & 207 & 436 & 0 & 0 & 0 & 0 & 0 & 0 & 0 & 0 \\
\hline 3-Methoxyluteolin & 296 & 0 & 0 & 0 & 0 & 0 & 0 & 0 & 0 & 0 & 0 & 0 & 0 & 0 & 0 & 0 \\
\hline 6-Hydroxyluteolin-5-glucoside & 0 & 0 & 0 & 0 & 0 & 0 & 0 & 0 & 0 & 0 & 0 & 0 & 893 & 0 & 835 & 1830 \\
\hline Luteolin & 292 & 0 & 0 & 0 & 0 & 0 & 0 & 0 & 0 & 0 & 0 & 0 & 4369 & 0 & 0 & 3239 \\
\hline Apigenin & 404 & 0 & 0 & 234 & 201 & 0 & 0 & 0 & 0 & 0 & 0 & 212 & 0 & 0 & 0 & 419 \\
\hline Hispidulin & 0 & 102 & 0 & 0 & 461 & 88 & 70 & 195 & 931 & 579 & 1256 & 1198 & 711 & 0 & 0 & 2227 \\
\hline Cirsimaritin & 0 & 452 & 946 & 0 & 1378 & 468 & 110 & 373 & 1559 & 2104 & 1269 & 1748 & 3258 & 0 & 172 & 5082 \\
\hline $\begin{array}{l}\text { The content of } \\
\text { hydroxycinnamic acids }\end{array}$ & 0.09 & 0.51 & 0.49 & 0.01 & 0.07 & 0.98 & 0.16 & 0.14 & 0.87 & 0.52 & 0.01 & 0.52 & 0.02 & 0.88 & 1.40 & 0.09 \\
\hline The content of flavonoids & 0.45 & 2.96 & 0.38 & 0.12 & 0.40 & 1.68 & 0.12 & 0.27 & 0.92 & 1.61 & 0.34 & 0.82 & 4.29 & 0.04 & 1.20 & 3.20 \\
\hline $\begin{array}{l}\text { Content of the sum of phenolic } \\
\text { compounds }\end{array}$ & 0.54 & 3.47 & 0.87 & 0.13 & 0.46 & 2.66 & 0.28 & 0.41 & 1.80 & 2.13 & 0.35 & 1.34 & 4.29 & 0.92 & 2.59 & 3.28 \\
\hline
\end{tabular}


and phenolic compounds were analyzed in 17 species of Salvia from different morpho-taxonomic groups. The coefficients of originality, the informational content of the sign, the sums of positive normal and qualified states of signs used for further calculations in taxonomy, as well as the coefficients of pair and group affinity were calculated. According to the results of the chemotaxonomic analysis conducted, the dendrogram with S. nemorosa in its base was constructed by chemical signs (Fig. 1).

The results of our chemotaxonomic studies of 17 species of the Salvia genus allowed us to solve a number of discussion questions regarding to the identity of the species that were identified: $S$. cernua and $S$. pendula; S. sylvestris and S. nemorosa; and $S$. illuminata and $S$. nemorosa. All these species turned out to be independent, showing a relation degree at the level of $13 \%$ S. cernua and S. pendula; 20\%-S. sylvestris and S. nemorosa; $31 \%$ - S. illuminata and $S$. nemorosa.

Four main clusters of species, which contain 1,8-cineole, rosmarinic acid, isovitexin-8-C-beta-glucoside (vicenin 2); apigenin and gispidulin; quercetin and rutin; $p$-cimen, kaempferol, hispidulin, and apigenine derivatives, were established. The first one includes $S$. officinalis L., S. grandiflora Etl., S. verbenata L., which contain p-cymen, $\beta$-pinene, 1,8-cineole, limonene, translinalool oxide, camphor, borneol, linalool, linalyl acetate, myrtenol, caryophyllene, caryophyllene oxide, viridiflorol, $\beta$-caryophyllene, luteolin, apigenin, and diosmetin-luteol-7-O-glucoside. The second one has S. pratensis L., S. stepposa Schost., S. Sibthorpii Sm., S. illuminata, S. nemorosa L., S. nutans L., which characterized by $\alpha$-pinene, 1,8-cineole, limonene, cis-neophytadiene, caffeic acid, 8 derivatives of caffeic acid, rosmarinic acid, hispidulin and cirsimaritin. The third cluster ( $S$. glutinosa L., $S$. nemorosa L., $S$. austriaca Jacq., and $S$. verticillata $L$.) distinguishes with $p$-cimen, 1,8-cineole, limonene, cis-2-hexen-1-ol acetate, $\beta$-thujone, camphor, borneol, para-cimen-8-ol, $\gamma$-sitosterol, luteolin-7-Oglycoside, caffeic acid, 12 derivatives of caffeic acid and rosmarinic acid. The fourth group (S. aethiopis L., S. sylvestris L., S. pendula Besser) designates with $\alpha$-pinene, $\alpha$-pinene oxide, $\alpha$-thujone, p-cimen-8-ol, carvacrol, nerolidol, hexahydropharnesylacetone, viridiflorol, isocaryophyll-3,8(13)-diene-5-ol, luteolin-7-Oglycoside, apigenin-7-O-glycoside, apigenin aglycone, hispidulin, cirsimaritin, caffeic and rosmarinic acid.

The dendrogram (Fig. 1) shows the division of the taxons studied into several groups that formed branches. S. nemorosa branches off into $S$. austriaca and $S$. sibthorpii containing 1,8-cineol, rosmarinic acid, as well as vicenin-2 in a considerable amount.

The branch with $\mathrm{S}$. aethiopis in its base is represented by species that do not contain 1,8-cineol or contains it in an insignificant amount and characterized by the presence of apigenin and hispidulin. Unlike other species, the species with S. stepposa in their base are characterized by the presence of quercetin and rutin. For species of the group with S. austriaca in its base, the presence of terpenoids - camphane derivatives and p-cymene unlike other species, flavonoids - hispidulin and derivatives of apigenin is typical.

According to the results of the chemotaxonomic study conducted for the first time, the chemical profile of the Salvia genus has been determined; it is characterized by terpenoids ( $\alpha$ - and $\beta$-pinene), camphane derivatives (camphene, camphor, and borneol), p-cymene, 1,8-cineol, limonene; phenolic compounds (caffeic and rosmarinic acids); and flavonoids (cynaroside, cosmosiin, hispidulin, and cirsimaritin), which are markers of the genus.

The novelty of the studies is that for the first time on the basis of morphological and chemical characteristics of 17 Salvia species,

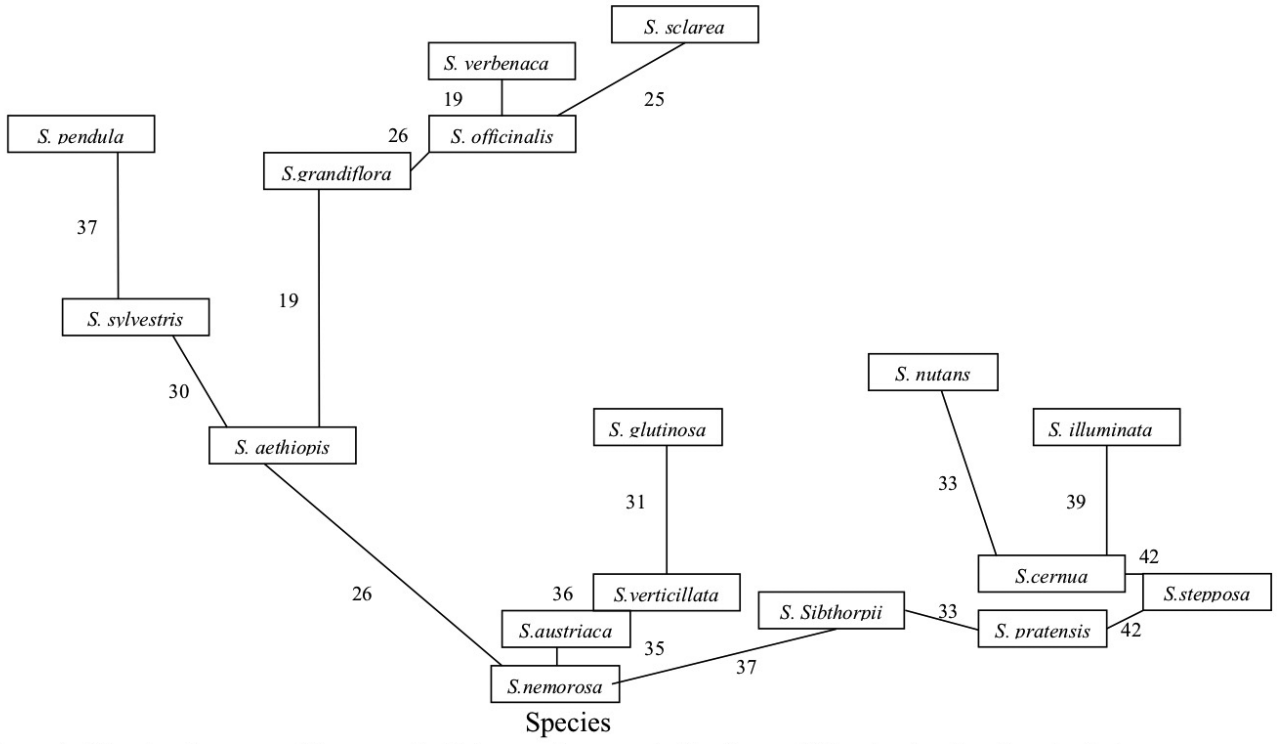

Figure 1: The dendrogram of taxonomic distances for sage in the flora of Ukarine by the chemical signs. 


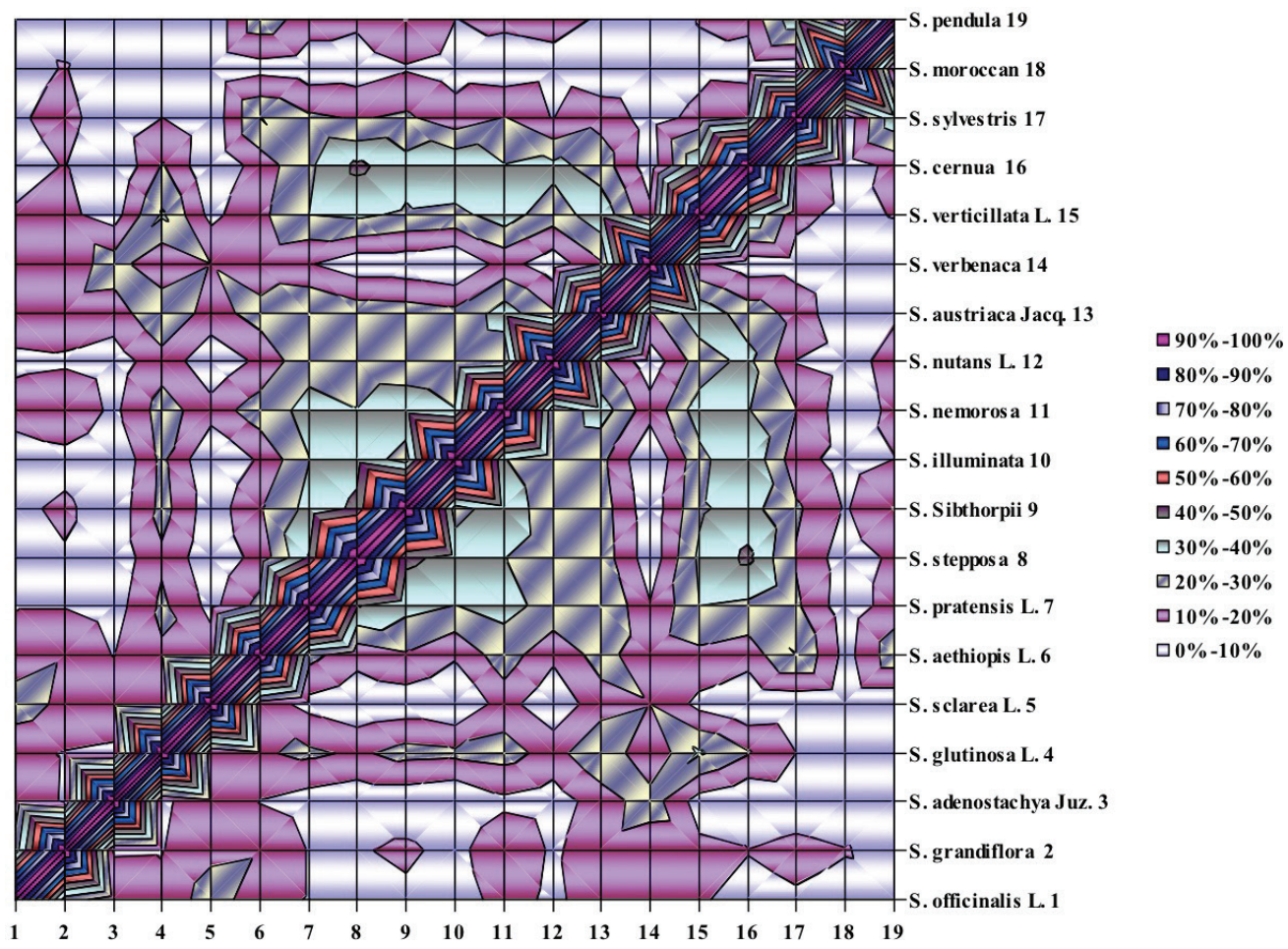

Figure 2: Diagram of taxonomic distances of species of the Salvia spp. based on the study of the terpenoid and phenolic composition of the sage in the flora of Ukraine.

which are present in the flora of Ukraine, chemotaxonomic studies were carried out and four main clusters of species were established, which made it possible to solve a number of discussion questions regarding the identity of species, to show some aspects of evolutionary development of Salvia species in Ukrainian flora and created the prerequisites for a targeted search for the biologically active substances among representatives of this genus.

\section{CONCLUSION}

The Salvia spp. from Ukraine were characterized by the presence of monoterpenoids such as $\alpha$ - and $\beta$-pinene, camphane derivatives (camphene, camphor, borneol), $p$-cymene, 1,8-cineol, limonene; and hydroxycinnamic acids - derivatives of caffeic acid (caffeic and rosmarinic acids) and flavonoids - derivatives of luteolin and apigenin (cynaroside, cosmosiin, hispidulin, and cirsimaritin). The highest content of terpenoids has been observed in the leaves of $S$. officinalis, S. grandiflora, and S. scabiosifolia; the highest content of hydroxycinnamic acids in the leaves of $S$. pratensis, $S$. illuminata, S. austriaca, and S. verticillata; the highest content of flavonoids and phenolic compounds was found in the leaves of $S$. grandiflora, S. pratensis, S. illuminata, S. nemorosa, S. pendula, $S$. sylvestris, $S$. nutans, $S$. verticillata, and $S$. cernua. The most promising species for use in the pharmaceutical industry are S. grandiflora, S. cernua, S. pratensis, S. nemorosa, and $S$. verticillata, which are mostly related to $S$. officinalis and contain a significant amount of phenolic compounds and terpenoids.

\section{FUNDING}

This research did not receive any specific grant from funding agencies, neither from the public, commercial, or not-for-profit sectors.

\section{CONFLICTS OF INTEREST}

Authors declare that they do not have any conflicts of interest.

\section{REFERENCES}

1. Jash SK, Gorai D, Roy R. Salvia genus and triterpenoids. Int J Pharm Sci Res 2016;7(12):4710-32.

2. Salvia. Flora SSSR. Vol. 21, Komarov VL (ed.). Moscow-Leningrad: USSR Academy of Sciences, 1954 (in Russian).

3. State Pharmacopoeia of Ukraine. Vol. 2, Kharkiv: RIREG, 2008 (in Ukrainian).

4. State Pharmacopoeia of Ukraine. Vol. 4, Kharkiv: RIREG, 2011 (in Ukrainian).

5. Koshovyi OM. Terpenoid composition of some representatives of the Eusalvia subgenus of the genus Salvia. Pharm Rev 2012;3:46-50 (in Ukrainian).

6. Janicsak G, Zupko I, Mathe I, Hohmann J. Comparative study of the antioxidant activities of eleven Salvia species. Nat Prod Commun 2010;5(2):227-30.

7. Firuzi O, Miri R, Asadollahi M, Eslami S, Jassbi AR. Cytotoxic, antioxidant and antimicrobial activities and phenolic contents of eleven Salvia species from Iran. Iran J Pharm Res 2013;12(4):801-10.

8. Li YJ, Duan CL, Liu JX, Xu YG. Pro-angiogenic actions of salvianolic acids on in vitro cultured endothelial progenitor cells and chick embryo chorioallantoic membrane model. J Ethnopharmacol 2010;131(3):562-6.

9. Eidi M, Eidi A, Zamanizadeh H. Effect of Salvia officinalis L. leaves on serum glucose and insulin in healthy and streptozotocin-induced diabetic rats. J Ethnopharmacol 2005;100(3):310-3.

10. Eidi M, Eidi A, Bahar M. Effects of Salvia officinalis L. (sage) leaves on memory retention and its interaction with the cholinergic system in rats. Nutrition 2006;22(3):321-6.

11. Tildesley NT, Kennedy DO, Perry EK, Perry EK, Ballard KA, Wesnes KA, et al. Positive modulation of mood and cognitive performance following administration of acute doses of Salvia 
lavandulaefolia essential oil to healthy young volunteers. Physiol Behav 2005;83(5):699-709.

12. Akhondzadeh S, Noroozian M, Mohammadi M, Ohadinia S, Jamshidi A, Khani M. Salvia officinalis extract in the treatment of patients with mild to moderate Alzheimer's disease: a double blind, randomized and placebo-controlled trial. J Clin Pharm Ther 2003;28:53-9.

13. Akhondzadeh S, Abbasi SH. Herbal medicine in the treatment of Alzheimer's disease. Am J Alzheimer's Dis Other Dementias 2006;21(2):113-8.

14. Koshevoi ON. Amino-acid and monosaccharide compositions of Salvia officinalis leaves. Chem Nat Compd 2011;47(3):492-3.

15. Koshovyi OM, Zaycev GP, Kovalyova AM, Komissarenko AM. Phenolic composition of leaves of some Salvia species of Ukraine. In: Collection of scientific works of NMAPO named after P. L. Shupyk. pp 305-310, 2012, (in Ukrainian).

16. Koshovyi ON, Vovk GV, Akhmedov EY, Komissarenko AN. The study of the chemical composition and pharmacological activity of Salvia officinalis leaves extracts getting by complex processing. Azerbaijan Pharm Pharmacother J 2015;15:30-4.

17. Jassbi AR, Zare S, Firuzi O, Xiao J. Bioactive phytochemicals from shoots and roots of Salvia species. Phytochem Rev 2016;15(5): 829-67.

18. Hegnauer R. Chemotaxonomie der Pflanzen. Basel: Birkhauser, 1962.

19. Harborne JB, Turner BL. Plant chemosystematics. London, UK: Academic Press, 1997.

20. Valant-Vetschera KM, Roitman JN, Wollenweber E. Chemodiversity of exudate flavonoids in somemembers of the Lamiaceae. Biochem Syst Ecol 2003;31(11):1279-89.

21. Wink M. Evolution of secondary metabolites from an ecological and molecular phylogenetic perspective. Phytochem 2003;64(1):3-19.

22. Liu K, Abdullah AA, Huang M, Nishioka T, AKang L, Azian Azamimi A, et al. Novel approach to classify plants based on metabolite-vontent similarity. Biomed Res Int 2017.

23. Holeman M, Berrada M, Bellakldar J, Lildrissi A, Pinel R. Etude Chimique Comparative de Huiles Essentielles de Salvia officinalis, $S$. aucheri, $S$. verbenaca, S. phlomoides et $S$. argentea. Fitoterapia 1983;55(3):143-8.

24. Coassini Lokar L, Moneghini M. Terpenes of Salvia species leaf oils: chemosystematic implications. Studia Geobotanica 1990;10:105-17.

25. Salimpour F, Mazooji A, Darzikolaei SA. Chemotaxonomy of six Salvia species using essential oil composition markers. J Med Plants Res 2011;5(9):1795-805.

26. K1lı̧ T, Dirmenci T, Gören AC. Chemotaxonomic evaluation of species of Turkish Salvia: Fatty acid composition of seed oils. II. Rec Nat Prod 2007;1(1):17-23.

27. Ozer H, Kilic H, Baris O, Adiguzel A. Composition of the essentiol oil of Salvia longipedicellata from Turkey. Chem Nat Prod 2007;43: 175-9.

28. Bigham AK, Munro TA, Rizzacasa MA, Robins-Browne RM. Divinatorins A-C, new neoclerodane diterpenoids from the controlled sage Salvia divinorum. J Nat Prod 2003;66(9):1242-4.

29. Dobrochaeva DN, Kotov MI, Prokudin YuN, Barbarich AI. Key to higher plants of Ukraine. 2nd edition, Kiev: Science Dumka, 1999 (in Russian).
30. Zenkevich IG. Analytical parameters of components of essential oils for their GC and GC-MS identification. Acetates of terpenic alcohols. Rastitel'nye Resursy 1999;35:30-7 (in Russian).

31. Chernogorod LB, Vinogradov BA. Essential oils of some species of the genus Achillea L., containing fragranol. Plant Res 2006;42(2): 61-8 (in Russian).

32. Chernyavsky AV, Terentyev NG. Study of species of the genus Salvia L. Flora of Ukraine with the help of discriminatory analysis. Ukrainian Bot J 1987;44:63-7 (in Russian).

33. Sydora NV, Kovalyova AM, Kovalev SV, Vilker AL. Chemotaxonomic study of the genus Crataegus L. In: Medicince and life : International Medical and Pharmaceutical Congress, Kyiv, Ukraine. pp 108-109, 2007 (in Ukrainian).

34. Kovalyova AM, Kovalyov VN, Sidora NV, Komissarenko AN. Contemporary approaches to the search for plant biological active substances and to determination of the plants place in the phylogenetic system on the basis of multidimensional taxonomy analysis techniques. In: The Regional Conference and Scientific Exhibition on Medicinal, Aromatic and Poisonous Plants. Sana'a, Yemen, pp 77-78, 2007.

35. Raal A, Orav A, Arak E. Composition of the essential oil of Salvia officinalis L. from various European countries. Nat Prod Res 2007;21(5):406-11.

36. Shinjyo N, Green J. Are sage, rosemary and lemon balm effective intervention in dementia? A narrative review of the clinical evidence. Eu J Integr Med 2017;15:83-96.

37. Velickovic AA, Smelecerovic NV, Randjelovic DT. Chemical constituents and antimicrobial activity of the ethanol extracts obtained from the flower, leaf and stem of Salvia oficinalis L. J Serbian Chem Soc 2003;68(1):126-31.

38. Wu YB, Ni ZY, Shi QW, Dong M, Kiyota H, Gu YC, et al. Constituents from Salvia species and their biological activities. Chem Rev 2012;112(11):5967-6026.

39. $\mathrm{Xu} \mathrm{J}$, Wei $\mathrm{K}$, Zhang $\mathrm{G}$, Lei $\mathrm{L}$, Yang $\mathrm{D}$, Wang $\mathrm{W}$, et al Ethnopharmacology, phytochemistry, and pharmacology of Chinese Salvia species: a review. J Ethnopharmacol 2018;225:18-30.

40. Mahdizadeh R, Moeln S, Soltani N, Malekzadeh K, Moein M. Study of molecular mechanism of Salvia species in prevention of diabetes. Int J Pharm Sci Res 2018;9(11):4512-21.

41. Lopresti AL. Salvia (sage): a review of it potential cognitive-enhancing and protective effects. Drugs Res Dev 2017;17(1):53-64.

42. Kalaycioglu Z, Uzasci S, Dirmenci T, Erim FB. Glucosidase enzyme inhibitory effects and ursolic and oleanolic acid contents of fourteen Antolian Salvia species. J Pharm Biomed Anal 2018;155:284-7.

How to cite this article:

Koshovyi O, Raal A, Kovaleva A, Myha M, Ilina T, Borodina N, Komissarenko A. The phytochemical and chemotaxonomic study of Salvia spp. growing in Ukraine. J Appl Biol Biotech 2020;8(03):029-036. DOI: 10.7324/JABB.2020.80306 